\title{
EVALUASI TINGKAT PENERIMAAN APLIKASI DATA POKOK PENDIDIKAN (DAPODIK) MENGGUNAKAN METODE TECHNOLOGY ACCEPTANCE MODEL (TAM) (Studi Kasus : Pemutakhiran Data PIP Menggunakan Aplikasi DAPODIK)
}

\author{
Muhammad Sukri $^{1}$, Aryanto $^{2}$, Risnal Diansyah ${ }^{3}$ \\ ${ }^{123}$ Fakultas Ilmu Komputer, Universitas Muhammadiyah Riau \\ 1email: M_Sukri@umri.ac.id \\ 2email: aryanto@umri.ac.id \\ 3email: risnal@umri.ac.id
}

\begin{abstract}
Smart Indonesia Program (PIP) is a direct cash assistance provided to underprivileged students with Smart Indonesia Card (KIP) as a marker / identity to ensure and ensure that children get the assistance of the Smart Indonesia Program. In order to monitor the distribution of KIP and to ensure that KIP has been accepted and can be utilized by the students, the Ministry of Education and Culture shall validate and update KIP recipient data through the Dapodik Application. Dapodik is an online and real time, based application that can be accessed and operated directly by all school operators in data entry, data processing, updating of PIP data, education personnel, students, periodic, sanitation, study groups and data of infrastructure school. This study aimed to evaluate the level of acceptance of basic education data applications (dapodik) using the method of Technology Acceptance Model (TAM). This study used 3 modified variables are Perceived Ease of Use (PEOU) and Perceived Usefulness (PU) as independent variable while Acceptance of IT as dependent variable. This study used simple random sampling as a sampling technique, with the number of respondents as many as 66 people operators. For data analysis techniques, this study used multiple regression techniques with descriptive quantitative research types, as well as data processing tools using SPSS 16.00 for windows software. The results showed that the benefit factor (Perceived Ease of Use) of 43.5\%, factor amenity (Perceived Usefulness) of 36.8\%. This proves that the more dominant benefit factor influences receipt of Dapodik application usage as PIP data updating application.
\end{abstract}

Key Words: Aplication of Dapodik, Perceived Ease of Use, Perceived Usefulness, Perceived Usefulness, Acceptance of IT, Technology Accaptance Model

\begin{abstract}
Abstrak
Program Indonesia Pintar (PIP) merupakan bantuan langsung tunai yang diberikan pada peserta didik yang kurang mampu dengan Kartu Indonesia Pintar (KIP) sebagai penanda/identitas untuk menjamin dan memastikan agar anak mendapat bantuan Program Indonesia Pintar. Dalam rangka untuk melakukan pemantauan terhadap distribusi KIP dan untuk memastikan bahwa KIP telah diterima dan dapat dimanfaatkan oleh siswa, maka Kementerian Pendidikan dan Kebudayaan melakukan validasi dan pemutakhiran data penerima KIP melalui Aplikasi Dapodik. Dapodik merupakan aplikasi berbasis online dan real time, yang dapat di akses dan operasikan langsung oleh seluruh operator sekolah dalam melakukan penginputan data, pengolahan data sekolah, pemutakhiran data PIP, tenaga kependidikan, peserta didik, periodik, sanitasi, rombongan belajar dan data saranaprasarana sekolah. Penelitian ini bertujuan untuk mengevaluasi tingkat penerimaan aplikasi data pokok pendidikan (dapodik) menggunakan metode Technology Acceptance Model (TAM). Dalam penelitian ini menggunakan 3 variabel yang dimodifikasi yaitu Perceived Ease of Use (PEOU) dan Perceived Usefulness (PU) sebagai variabel independen sedangkan Acceptance of IT sebagai variabel
\end{abstract}


dependen. Teknik pengambilan sampel menggunakan simple random sampling, dengan jumlah responden sebanyak 66 orang operator. Untuk teknik analisis data menggunakan teknik regresi ganda dengan jenis penelitian deskriptif kuantitatif, serta alat pengolahan data menggunakan software SPSS 16.00 for windows. Hasil penelitian menunjukkan bahwa factor manfaat (Perceived Ease of Use) sebesar 43,5\%, factor kemudahan (Perceived Usefulness) sebesar 36,8\%. Hal ini membuktikan bahwa factor manfaat yang lebih dominan berpengaruh terhadap penerimaan penggunaan Aplikasi dapodik sebagai Aplikasi pemutakhiran data PIP.

Kata Kunci: Aplikasi Dapodik, Perceived Ease of Use, Perceived Usefulness, Perceived Usefulness, Acceptance of IT, Technology Accaptance Model. 


\section{PENDAHULUAN}

Kartu Indonesia Pintar (KIP) diberikan sebagai penanda/identitas untuk menjamin dan memastikan agar anak mendapat bantuan Program Indonesia Pintar apabila anak telah terdaftar atau mendaftarkan diri (jika belum) ke lembaga pendidikan formal (sekolah/madrasah) atau lembaga pendidikan non formal (Pondok Pesantren, Pusat Kegiatan Belajar Masyarakat/PKBM, Paket A/B/C, Lembaga Pelatihan/Kursus dan Lembaga Pendidikan Non Formal lainnya di bawah Kementerian Pendidikan dan Kebudayaan dan Kementerian Agama).

Dalam rangka untuk melakukan pemantauan terhadap distribusi KIP dan untuk memastikan bahwa KIP telah diterima dan dapat dimanfaatkan oleh siswa, maka Kementerian Pendidikan dan Kebudayaan melakukan validasi penerimaan KIP melalui Aplikasi Dapodik. Secara teknis yang harus dilakukan adalah anak yang telah menerima KIP untuk melaporkan ke satuan pendidikan tempat anak mengikuti pendidikan (sekolah, sanggar kegiatan belajar, pusat kegiatan belajar masyarakat, dan lembaga kursus dan pelatihan) untuk mencatatkan data KIP ke Aplikasi Dapodik di satuan pendidikan tersebut.

Berdasarkan Surat Edaran Nomor 9 Tahun 2016, Tentang Percepatan Pelaporan Dan Penyaluran Dana Kartu Indonesia Pintar (KIP) Tahun 2016, bahwa mulai bulan April 2016 Kementerian Pendidikan Dan Kebudayaan telah mengirimkan 17,9 juta KIP ke alamat rumah tangga anak usia 6-12 tahun melalui PT. Satria Antaran Prima dan PT. Dexter Ekspressindo. Namun sampai dengan saat ini jumlah peserta didik yang melaporkan Kartu Indonesia Pintar (KIP) kepada sekolah/lembaga pendidikan melalui Data Pokok Pendidikan (Dapodik) baru sejumlah 7,541,493 (rekapitulasi data pada laman

http://data.dikdasmen.kemdikbud.go.id/kipinfo per 02 Mei 2017).

Dapodik merupakan aplikasi berbasis online dan real time yang dikembangkan pada tahun 2006 oleh Biro Perencanaan dan
Kerjasama Luar Negeri dikenal dengan Biro PKLN Depdiknas dimasa itu. Aplikasi ini dapat di akses dan operasikan langsung oleh seluruh operator sekolah dalam melakukan penginputan data, pengolahan data sekolah, tenaga kependidikan, peserta didik, periodik, sanitasi, rombongan belajar dan data sarana-prasarana sekolah. Aplikasi ini dibangun dalam rangka untuk mendapatkan data yang dibutuhkan dengan cepat, lengkap, valid dan up to date.

Berdasarkan kendala diatas terlihat adanya permasalahan antara aplikasi/ Sistem Informasi Dapodik dengan Operator sekolah dan Operator PIP SD Di Dinas Kabupaten/ Kota. Permasalahan ini akan mempengaruhi penerimaan pengguna terhadap Sistem Informasi Dapodik tersebut. Oleh karena itu perlu di lakuan evaluasi pemanfaatan aplikasi dapodik terhadap pemutakhiran data PIP ditinjau dari faktor kemudahan (perceived ease of use) dan manfaat (perceived usefulness) yang ada pada sistem dengan menggunakan metode Technology Acceptance Model (TAM).

\section{METODE PENELITIAN}

\subsection{Proses Alur Penelitian}

Untuk memudahkan dalam menjelaskan proses demi proses yang dilakukan dalam penelitian, maka proses alur penelitian disajikan dalam bentuk bagan seperti berikut ini: 


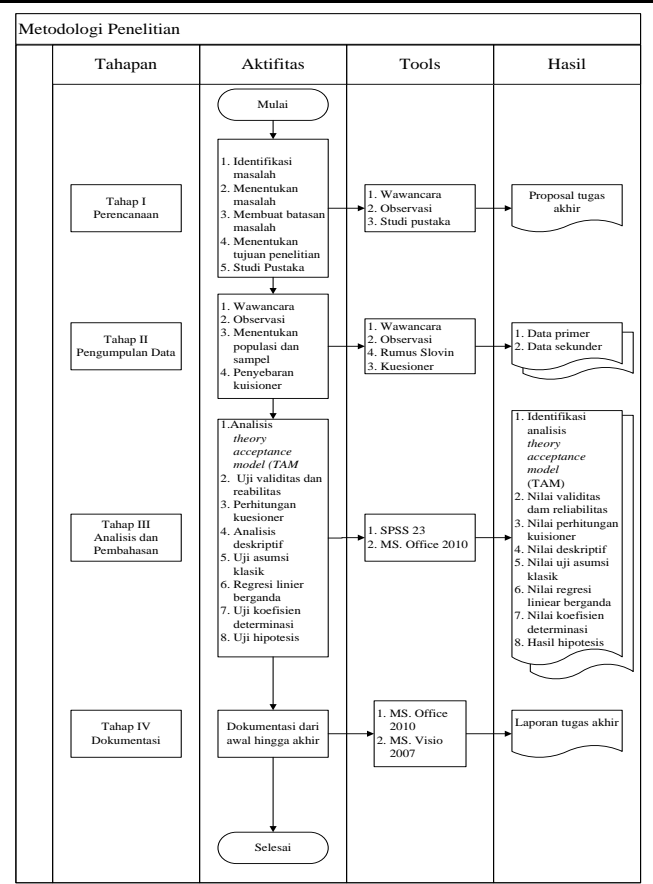

1. Menentukan Topik Penelitian

2. Menentukan Lokasi Objek Penelitian

\section{Studi Pendahuluan}

\subsubsection{Tahap Perencanaan}

Tahapan kedua yang dilakukan pada penelitian ini adalah sebagai berikut:

1. Rumusan Masalah, Batasan Masalah, Tujuan dan Manfaat Penelitian. Pada tahap ini dirumuskan permasalahan apa yang akan dikaji dan menentukan batasan masalahnya serta memembuat tujuan dan manfaat yang hendak dicapai seperti yang telah diuraikan pada BAB I.

\section{Menentukan Kebutuhan Data}

Pada tahap ini akan ditentukan data-data apa saja yang akan dibutuhkan dalam Tugas Akhir. Penentuan data ini dilakukan setelah melakukan studi pedahuluan yaitu observasi dan wawancara di lingkungan kantor Dinas Pendidikan dan Kebudayaan Kabupaten Kampar. Guna untuk membantu menentukan data seperti apa yang diperlukan dalam menganalisis penerimaan pengguna Aplikasi dapodik.

3. Menentukan Teknik dan Alat Pengumpulan Data

Dalam pengumpulan data pada penelitian ini sebelumnyan perlu ditentukan teknik dan alat-alat pengumpulan data yang akan digunakan. Untuk menentukan teknik pengumpulan data, maka dilakukan studi pendahuluan yaitu penyebaran kuisoner dan wawancara ke operator sekolah alat apa yang bisa di terapkan. Setelah teknik pengumpulan data ditentukan, maka ditentukanlah alat untuk mengumpulkan datanya, yaitu angket dan studi literatur.

\section{Menentukan Hipotesis}

Hipotesis ini dibuat guna untuk mendapatkan jawaban sementara terhadap penelitian dan memfokuskan terhadap jawaban akan dicapai yaitu hasil pengujian pengaruh setiap variabel-variabel pada penelitian ini. Hasil dari tahapan perencanaan ini adalah Proposal Tugas Akhir.

\subsubsection{Tahap Pengumpulan Data}

1. Menyebarkan Angket

2. Uji Validitas dan Reliabilitas Angket

3. Studi Literatur dan Pustaka

\subsubsection{Tahap Analisa Dan Pembahasan}

Pada tahapan ini kegiatan yang dilakukan adalah:

\section{Analisis Deskriptif}

Pada penelitian ini akan menjelaskan frekuensi profil responden, deskriptif data hasil penelitian dan persentase (\%) tingkat penerimaan pengguna terhadap Aplikasi Dapodik. 
2. Uji asumsi klasik

Uji asumsi klasik merupakan uji persyaratan regresi linear ganda.

$$
d=\frac{\sum_{t=2}^{t=N}\left(e_{t}-e_{t-1}\right)^{2}}{\sum_{t=2}^{t=N} t^{2}}
$$

Dimana:

et $=$ kesalahan gangguan dari sampel

et-1= kesalahan gangguan dari sampel satu periode sebelumnya

Ketentuan:

a. Angka D-W dibawah -2 berarti ada autokorelasi

b. Angka DW diantara -2 sampai 2 berarti tidak ada autokorelasi

c. Angka DW diatas 2 berarti ada autokorelasi

c. Uji Heteroskedastisitas

Untuk mendeteksi ada tidaknya heteroskedastisitas adalah dengan cara melihat Grafik Plot antara nilai prediksi variabel terikat yaitu ZPRED dan residualnya SRESID. Jika gambar membentuk pola tertentu maka ada masalah heteroskedastisitas dan jika tidak membentuk berarti tidak ada masalah heteroskedastisitas. (Ghozali, 2007).

\section{d. Uji Normalitas}

Uji normalitas bertujuan untuk menguji apakah dalam model regresi, variabel pengganggu (residual) memiliki distribusi normal, seperti diketahui, uji $t$ dan uji $F$ mangasumsikan bahwa nilai residual mengikuti distribusi normal. Deteksi normalitas dilakukan dengan melihat penyebaran data (titik) pada sumbu diagonal dari grafik. Jika data menyebar di sekitar garis diagonal, maka model regresi memenuhi

\section{a. Uji Koefisien Korelasi}

Analisis korelasi dilakukan untuk mengetahui hubungan antara dua variabel (bivariate correlation) atau lebih dari dua variabel (multivariate correlaiton). Jika koefesien korelasi positif, maka kedua variabel mempunyai hubungan searah dan jika koefesien korelasi negatif, maka kedua variabel mempunyai hubungan terbalik.

\section{b. Uji Koefisien Determinasi}

Untuk mengetahui kecocokan garis regresi yang diperoleh. Semakin besar

nilai Adjusted R Square maka semakin kuat kemampuan model regresi yang diperoleh. Dan dapat diketahui dari besar kecilnya koefisien Adjusted R Square.

\section{c. Uji Signifikan Simultan (Uji Statistik F)}

Untuk mengetahui ada tidaknya pengaruh secara bersama-sama (simultan) variabel independen (bebas) terhadap variabel dependen (terikat).

d. Uji Signifikan Individual (Uji Statistik t) Untuk mengetahui berapa besar pengaruh masing-masing variabel bebas secara sendiri-sendiri dalam menjelaskan variabel terikatnya.

\section{Pengujian Hipotesis}

Pada proses ini akan dilakukan pengujian hipotesis berdasarkan analisis regresi linear ganda diatas. Untuk membuktikan kebenaran hipotesis digunakan uji statistik $\mathrm{F}$ dan uji statistik t, dengan tingkat signifikan $=0,05$.

5. Faktor dominan 
Pada proses ini yang akan dicari yaitu faktor yang lebih dominan terhadap variabel $\mathrm{Y}$ dengan melihat Coefficienst pada kolom standardized coefficients.

\subsection{Jenis Penelitian}

Jenis penelitian ini merupakan riset survey, yaitu metode pengumpulan Informasi dengan menyampaikan serangkaian pertanyaan yang telah diformulasikan sebelumnya dan urutan tertentu dalam sebuah kuesioner terstruktur kepada suatu sampel individu terpilih untuk menjadi wakil sebuah populasi terdefinisi. Kuesioner dan wawancara adalah teknik-teknik yang merupakan inti salah satu tipe riset survey (Sudaryono dkk, 2010).

\subsection{Sumber Data}

Sumber data dalam penelitian ini terdapat dua bagian yaitu, data primer dan data sekunder.

1. Data Primer

Data primer adalah data yang diperoleh secara langsung dari objek penelitian. Seperti data yang diperoleh dari hasil wawancara dan penyebaran angket kepada operator sekolah.

\section{Data Sekunder}

Data sekunder adalah data yang diperoleh dari data internal objek penelitian, seperti data yang diperoleh dari buku, jurnal, paper, dan alamat website rujukan yang ada kaitannya dengan judul penelitian.

\subsection{Populasi dan Sampel}

Sasaran populasi pada penelitian ini adalah seluruh Operator Sekolah pada tingkatan SD Negeri Kota Pekanbaru sebanyak 194 sekolah.

\subsection{Teknik Pengambilan Sampel}

Besarnya sampel yang akan diambil pada penelitian ini berdasarkan rumus Slovin.

\section{$\mathrm{N}$}

$\mathrm{n}=$

$1+\mathrm{N}$

$\mathrm{n}=$ Jumlah sampel

$\mathrm{N}=$ Ukuran populasi $\mathrm{e}=$ Persen kelonggaran ketidaktelitian karena kesalahan pengambilan sampel yang masih dapat ditolerir/diinginkan, misal $10 \%(0,1)$. Besar sampelnya adalah:

$$
\begin{aligned}
& \mathrm{n}=\frac{194}{1+(194)(0,1)} \\
& \mathrm{n}=\frac{194}{1+1,94} \\
& \mathrm{n}=\frac{194}{2,94} \\
& \mathrm{n}=65,98639 \text { (Dibulatkan menjadi } 66 \text { orang } \\
& \text { responden) }
\end{aligned}
$$

\subsection{Teknik Pengumpulan Data}

Pada teknik pengumpulan data, penulis menggunakan beberapa tahapan

yaitu:

\section{Angket}

Angket (questionnaire) adalah daftar pertanyaan yang diberikan kepada orang lain yang bersedia memberikan respon sesuai dengan permintaan penggunaan.

\section{Wawancara}

Wawancara adalah suatu cara pengumpulan data yang digunakan untuk memperoleh informasi langsung dari sumbernya.

\section{Pengamatan (Observation)}

Observasi adalah melakukan pengamatan secara langsung ke objek penelitian untuk melihat dari dekat kegiatan yang dilakukan.

\section{Kepustakaan (Literature)}

Cara ini dilakukan untuk mendapatkan dasardasar referensi yang kuat 


\section{HASIL DAN PEMBAHASAN}

\subsubsection{Tanggapan Responden Terhadap Pemanfaatan}

Pemanfaatan didefinisikan sebagai sejauh mana seseorang percaya bahwa menggunakan suatu teknologi akan meningkatkan kinerja pekerjaan pengguna. Berikut tanggapan responden terhadap manfaat:

Tabel 4.6 Tanggapan Responden Terhadap Pemanfaatan

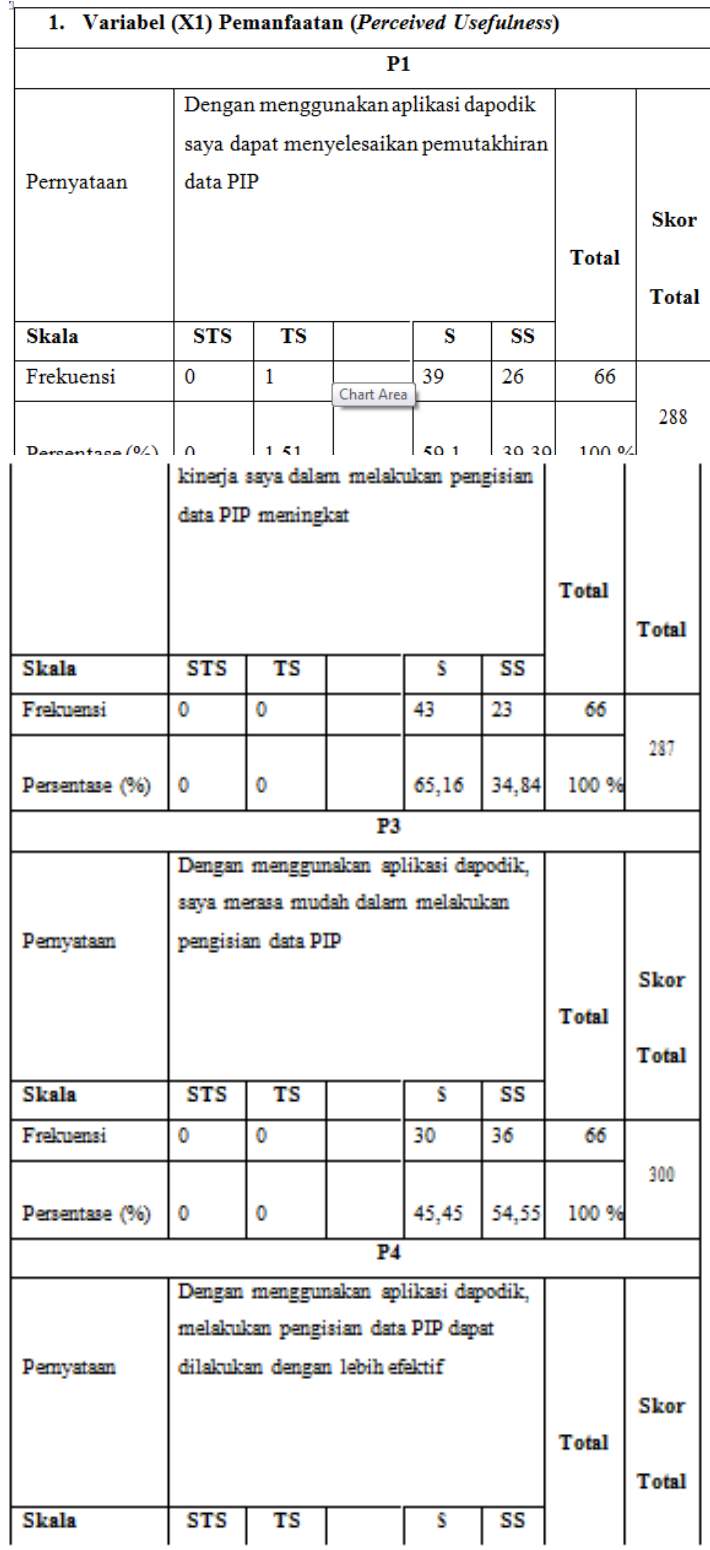

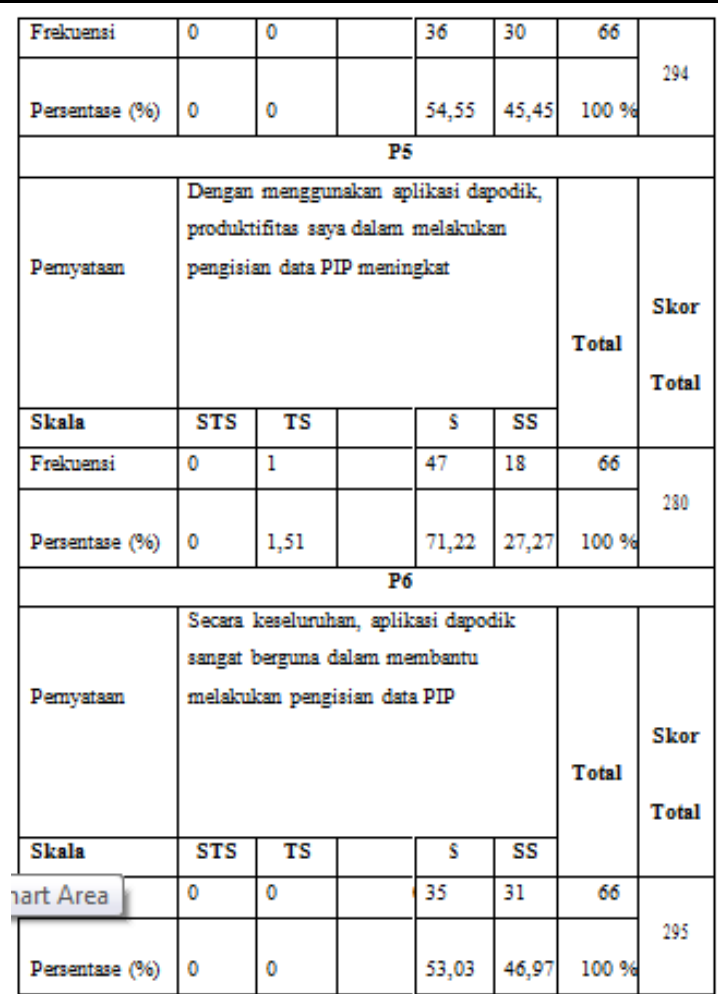

\subsubsection{Tanggapan Responden Terhadap} Kemudahan

Kemudahan penggunaan didefinisikan sebagai sejauh mana seseorang percaya bahwa menggunakan suatu teknologi akan bebas dari usaha. Berikut tanggapan responden terhadap kemudahan:

Tabel 4.7 Tanggapan Responden Terhadap Kemudahan 


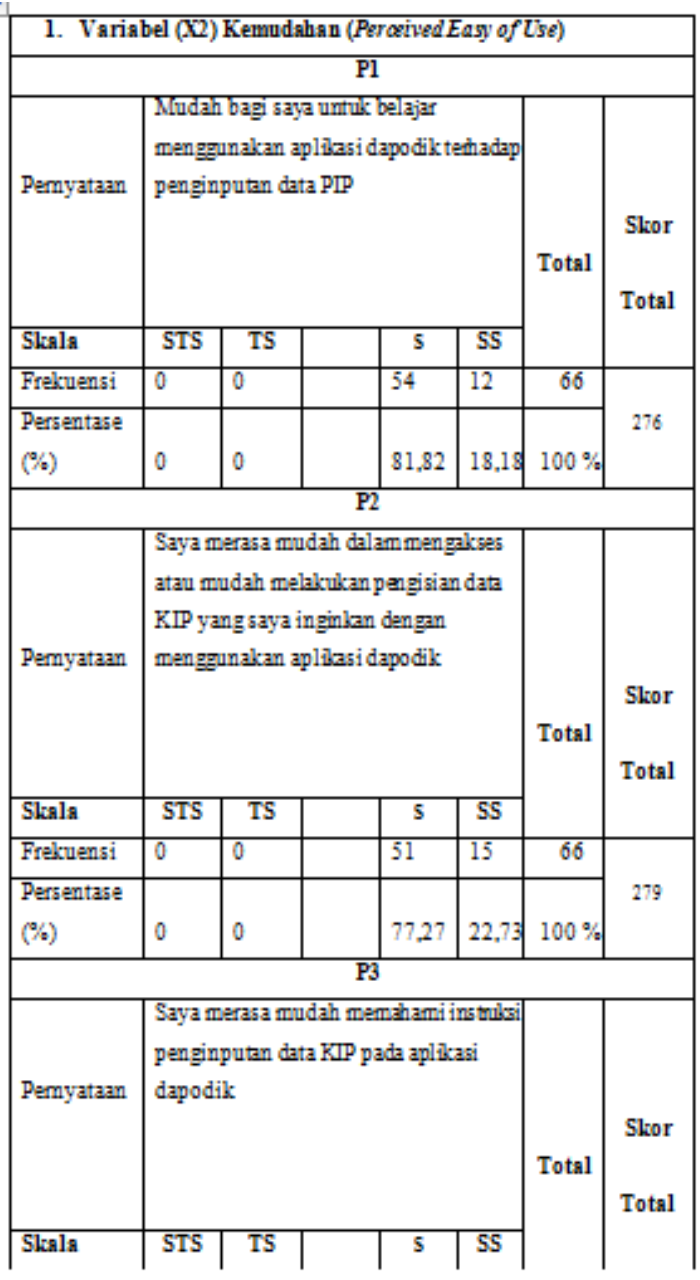

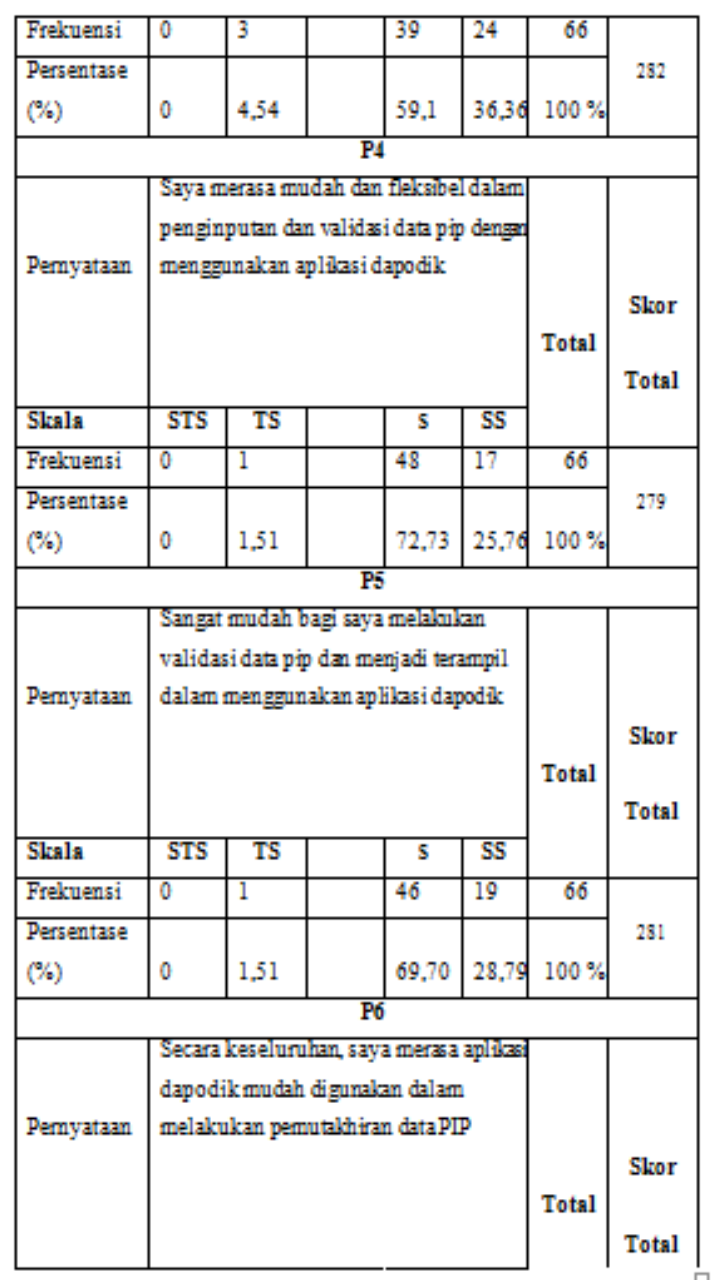

\begin{tabular}{|c|c|c|c|c|c|c|}
\hline & & & & & & \\
\hline \begin{tabular}{|l|} 
Slcala \\
\end{tabular} & \begin{tabular}{|l|} 
STS \\
\end{tabular} & TS & 5 & SS & & \\
\hline \begin{tabular}{|l} 
Frekuensi \\
\end{tabular} & 0 & 0 & 43 & 23 & 66 & \\
\hline $\begin{array}{l}\text { Persentase } \\
(\%)\end{array}$ & 0 & 0 & 65,15 & $34,8=$ & $100 \%$ & 287 \\
\hline
\end{tabular}

\subsection{3 Tanggapan Responden Terhadap Penerimaan Pengguna}

Penerimaan pengguna terhadap aplikasi dapodik dipengaruhi oleh kemudahan dan kemanfaatan yang di hasilkan oleh aplikasi dapodik tersebut. Sehingga kemudahan dan manfaat ini menjadi faktor penting bagi pengguna aplikasi dapodik untuk menerima dan menggunakan aplikasi dapodik yang ditawarkan.

Tabel 4.8 Tanggapan Responden Terhadap Penerimaan Pengguna 


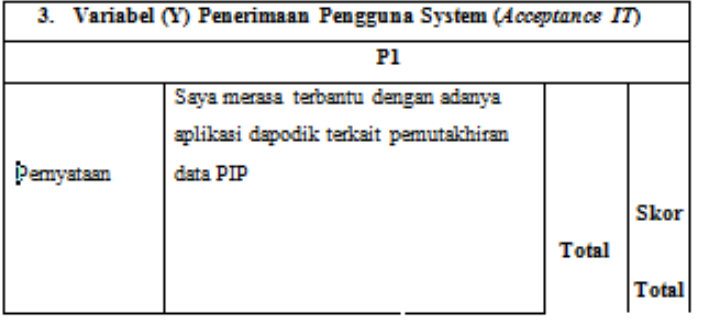

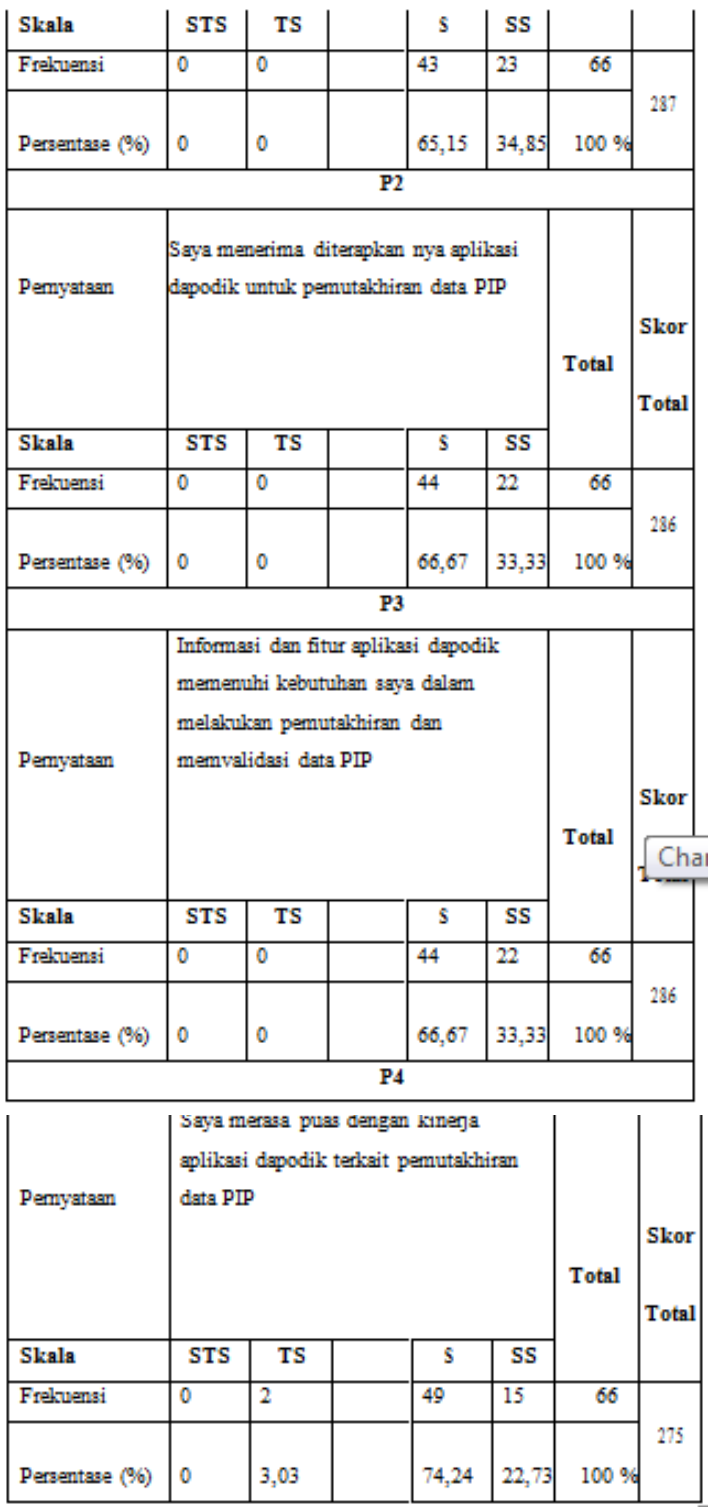

\subsection{3}

Uji Hipotesis

4.7.3.1 Uji Signifikan Bersamaan (Uji Statistik F)
Uji statistik $F$ pada dasarnya menunjukkan apakah semua variabel independen dalam model mempunyai pengaruh secara bersama-sama terhadap variabel dependen. (Mahyarni, dkk 2010).

ANOVA $^{b}$

\begin{tabular}{|c|c|c|c|c|c|}
\hline Model & $\begin{array}{l}\text { Sum of } \\
\text { Squares }\end{array}$ & Df & $\begin{array}{c}\text { Mean } \\
\text { Square }\end{array}$ & $\mathrm{F}$ & Sig. \\
\hline $\begin{array}{ll}1 & \text { Re } \\
& \text { gre } \\
& \text { ssi } \\
& \text { on } \\
& \text { Re } \\
& \text { sid } \\
& \text { ual } \\
& \text { Tot } \\
& \text { al }\end{array}$ & $\begin{array}{r}95.836 \\
83.982 \\
179.818\end{array}$ & 63 & $\begin{array}{r}47.918 \\
1.333\end{array}$ & $\begin{array}{r}35.94 \\
6\end{array}$ & $.000^{\mathrm{a}}$ \\
\hline
\end{tabular}

a. Predictors: (Constant),

$\mathrm{x} 2$ manfaat, $\mathrm{x} 1$ kemudahan

b. Dependent Variable:

ylpenerimaan

Pada Tabel 4.14 diatas, ternyata didapat $F_{\text {hitung }}$ adalah sebesar 35,946 dengan tingkat probabilitas 0,000, sedangkan $\mathrm{F}_{\text {tabel }}$ 3,14 dengan tingkat signifikan (alpha) 5\%. Jadi dapat disimpulkan bahwa $\mathrm{F}$ hitung $=35,946>3,14$. Dengan demikian pemanfaatan $\left(\mathrm{X}_{1}\right)$ dan kemudahan $\left(\mathrm{X}_{2}\right)$ secara bersama-sama berpengaruh signifikan terhadap penerimaan pengguna aplikasi dapodik dalam pemutakhiran data PIP (Y).

\section{SIMPULAN DAN SARAN}

\subsection{Kesimpulan}

Berdasarkan analisis data dalam penelitian yang telah dilakukan maka dapat disimpulkan sebagai berikut: 
1. Secara Deskriptif diperoleh hasil Penerimaan Pengguna aplikasi dapodik termasuk dalam kategori sangat setuju pada variabel manfaat yang dihasilkan oleh aplikasi dapodik sebesar 88,08\%. Dan pada variabel kemudahan yang dihasilkan oleh aplikasi dapodik berada dalam kategori sangat setuju sebesar $85,05 \%$. Dari hasil tersebut dapat dinyatakan bahwa pengguna merasa terbantu dengan adanya aplikasi dapodik dalam pemutakhiran data PIP dan sangat setuju bahwa aplikasi dapodik telah memenuhi kebutuhan pengguna dan pengguna menerima penerapan aplikasi dapodik dalam pemutakhiran data PIP di Dinas Pendidikan Kota Pekanbaru.

2. Hasil penelitian ini menunjukkan bahwa factor manfaat (Perceived of Usefulness/X1) dan factor kemudahan (Perceived Ease of Use/X2) secara signifikan bersama-sama berpengaruh positif terhadap tingkat penerimaan aplikasi dapodik dalam pemutakhiran data PIP (Y1). Hal ini dikarenakan pada uji $\mathrm{F}$ diperoleh nilai $\mathrm{F}$ hitung $>\mathrm{F}$ table $(35.946>3,14)$.

3. Hasil penelitian ini menunjukkan bahwa faktor manfaat (Perceived Usefulness/X1) secara signifikan berpengaruh positif terhadap tingkat penerimaan aplikasi dapodik dalam pemutakhiran data PIP (Y1). Hal ini dikarenakan pada uji regresi linear dan uji $\mathrm{T}$ diperoleh nilai $\mathrm{T}$ hitung $>\mathrm{t}$ table $(3,826>1,66940)$ dan besarnya pengaruh untuk factor manfaat terhadap penerimaan pengguna aplikasi dapodik dalam pemutakhiran data PIP sebesar 0,318 atau $31,8 \%$. Dari hasil tersebut dapat dinyatakan bahwa manfaat yang dihasilkan oleh aplikasi dapodik mempunyai hubungan yang cukup berarti terhadap penerimaan pengguna aplikasi dapodik dalam pemutakhiran data PIP.

4. Hasil penelitian ini menunjukkan bahwa factor kemudahan (Perceived Ease of Use/X2) secara signifikan berpengaruh positif terhadap tingkat penerimaan aplikasi dapodik dalam pemutakhiran data PIP (Y1). Hal ini dikarenakan pada uji regresi linear dan uji $\mathrm{T}$ diperoleh nilai $\mathrm{t}$ hitung $>\mathrm{t}$ table $(3,234>1,66940)$ dan besarnya pengaruh untuk factor kemudahan terhadap penerimaan pengguna aplikasi dapodik dalam pemutakhiran data PIP sebesar 0,271 atau 27,1\%. Dari hasil tersebut dapat dinyatakan bahwa kemudahan yang dihasilkan oleh aplikasi dapodik mempunyai hubungan yang cukup berarti terhadap penerimaan pengguna aplikasi dapodik dalam pemutakhiran data PIP.

5. Adapun faktor yang lebih dominan berpengaruh terhadap penerimaan pengguna aplikasi dapodik adalah faktor manfaat dengan nilai sebesar $43,5 \%$ sedangkan faktor kemudahan hanya sebesar $36,8 \%$.

\section{DAFTAR PUSTAKA}

Ghozali, Imam. "Aplikasi Analisis Multivariate Dengan Program SPSS". Edisi 4. Badan Penerbit Undip, Semarang. 2007

Harefa, A. "Sistem Informasi Perpustakaan di Badan Penelitian Dan Pengembangan Provinsi Sumatera Utara”. Jurnal. Fakultas Matematika Dan Ilmu Pengetahuan Alam Universitas Sumatera Utara, Medan. 2009

Hartono. "SPSS 16 Analisis Data Penelitian Dan Statistika". Pustaka Belajar, Yogyakarta. 2008

Hasan M. iqbal. "Pokok-Pokok Materi Statistik 2 (Statistik Inferensif)". Penerbit Bumi Aksara, Jakarta. 2008

Jogianto. "Sistem Informasi Keperilakuan". Edisi Revisi. Penerbit Andi Offset, Yogyakarta. 2007 
Kartika, S. "Analisis Proses Penerimaan Sistem Informasi Icons Dengan Menggunakan Technology Acceptance Model Pada Karyawan PT.Bank Negara Indonesia (Persero) Tbk". Jurnal. Universitas Diponegoro, Semarang. 2009

Kemdikbud. "Manual Aplikasi DAPODIKDAS 2013”. Kemdikbud, Jakarta. 2013

Mahfoedz, I. "Metodologi Penelitian bidang Kesehatan, keperawatan dan Kebidanan". Fitramaya, Yogyakarta. 2005

Mahyarni, Henni dan Astuti. "Analisis Faktor-Faktor Yang Mempengaruhi

Budaya Nasional Terhadap Kinerja Dosen Pada Perguruan Tinggi Agama Islam Di Provinsi Riau". Penelitian. Universitas Islam Negeri Sultan Syarif

Kasim, Pekanbaru. 2010

Oktavianti, Bramantika. "Evaluasi Penerimaan Sistem Teknologi Informasi Dengan Menggunakan Variabel Perceived Usefulness, Perceived Ease Of

Use, Dan Perceived Enjoyment (studi kasus: di PT Sanggar Sarana Baja pada Departemen Accounting dan Marketing)". Tesis. Program Studi

Magister Sains Akuntansi, Fakultas Ekonomi Universitas Gadjah Mada, Yogyakarta. 2007

Saputro, N. "Analisis Persepsi Penerapan Sistem Informasi Pada PT. Ups Dengan Menggunakan Metode Technology Acceptance Model (TAM)". Jurnal. Universitas Negeri Gorontalo, Gunadarma. 2011

Sudarmanto, Gunawan. "Analisis Regresi Linear Ganda Dengan SPSS". Graha Ilmu, Yogyakarta. 2005

Sudaryono, Guritno, dan Untung Rahardja, 2010. "Metodologi Penelitian Teknologi
Informasi”. Penerbitt Andi offset, Yogyakarta. 2010

Sulaiman, W. “Analisis Regresi Menggunakan SPSS". Penerbit Andi Offset, Yogyakarta. 2004

Surachman, A. "Analisis Penerimaan Sistem Informasi Perpustakaan (SIPUS) Terpadu Versi 3 Di Lingkungan Universitas Gadjah Mada (UGM)".Jurnal Perpustakaan Digital UIN Sunan Kalijaga Yogyakarta. 2008

Zakiyudin, Ais. "Sistem Informasi Manajemen. Penerbit Andi Offset, Yogyakarta. 2011 